\title{
A Study on Effects of Dexmedetomidine Used as an Adjuvant in Epidural Post-Operative Analgesia
}

\author{
Bhaidas Onkar Patil', Suhasini Ravindra Sonavdekar'2, Ranjan Mathur ${ }^{3}$
}

${ }^{1}$ Associate Professor, Department of Anaesthesia, SMBT Institute of Medical Sciences \& Research Center, Dhamangaon Tal. Igatpuri, Nashik, Maharashtra, India, ${ }^{2}$ Associate Professor, Department of Anaesthesia, MGM Medical College, Kamothe, Navi Mumbai, Maharashtra, India, ${ }^{3}$ Senior Professor and Head, Department of Dentistry, S. P. Medical College, Bikaner, Rajasthan, India.

\section{Abstract}

Background: Epidural anaesthesia with adjuvant is normally used for postoperative pain management in infra umbilical surgeries but search for ideal adjuvant without any side effect goes on. Aim: This study was done to assess the onset and duration of sensory and motor block and side effects of dexmedetomidine, when used as an adjuvant in epidural anaesthesia in infra umbilical surgeries. Subjects and Methods: 60 patients of ASA status I and II, posted for infra umbilical surgeries were randomly allocated into two groups of 30 each. Group L patients received epidural $0.5 \%$ levobupivacaine. Group LD patients received epidural $0.5 \%$ levobupivacaine and $1 \mu \mathrm{g} / \mathrm{kg}$ dexmedetomidine. Preoperative and postoperative block characteristics as well as hemodynamic parameters and side effects were monitored. Results: Dexmedetomidine as an adjuvant had an earlier onset and longer duration of sensory and motor block compared to levobupivacaine alone. Sedation scores were statistically significant with dexmedetomidine group in comparison to levobupivacaine alone group. Conclusion: Dexmedetomidine, as an adjuvant to epidural levobupivacaine provided prolonged analgesia in infraumbilical surgeries.

Keywords: Dexmedetomidine, levobupivacaine, infraumbilical surgeries.

Corresponding Author: Dr. Suhasini Ravindra Sonavdekar, Associate Professor, Department of Anaesthesia, MGM Medical College, Kamothe, Navi Mumbai, Maharashtra, India.

Received: June 2019

Accepted: June 2019

\section{Introduction}

Epidural anaesthesia provides both intra and post-operative pain relief in various infraumbilical surgeries. Epidural bupivacaine had been commonly used in the past decades for providing adequate post-op pain relief. ${ }^{[1]}$ The analgesic duration can be prolonged by increasing dose of local anaesthetics; however the risk of systemic cardiac and neurotoxicity can be increased. ${ }^{[2]}$ Therefore, adjuvant can be added to local anaesthetics to prolong the analgesic duration so that the amount of local anaesthetics can be restricted. Recemic bupivacaine is most frequently used long acting local anaesthetic agent in regional anaesthesia. But the low dose bupivacaine is often used in order to reduce cardiovascular side effects which may not provide adequate postoperative analgesia. ${ }^{[3]}$ Levobupivacaine is the isolated $\mathrm{S}$ (-) isomer of bupivacaine. Due to lower affinity of $\mathrm{S}(-)$ isomer to cardiac sodium channel compared to $\mathrm{R}$ isomer, it is less cardio toxic. ${ }^{[4]}$ So we have chosen levobupivacaine as the local anaesthetic as it is longer acting and devoid of any cardiac side effects. Recently, several neuraxial adjuvants, including clonidine, opioids, dexamethasone, ketamine, magnesium sulphate and midazolam have demonstrated the synergistic analgesic effect with local anaesthetics with varying degrees of success. But the search for ideal adjuvant for a particular local anaesthetic agent goes on. ${ }^{[5]}$
Literature is available using $\alpha-2$ agonists like clonidine as adjuvant to local anaesthetics like bupivacaine, levobupivacaine and ropivacaine in epidural route but very few are there regarding their use with dexmedetomidine. $\alpha$ 2 adrenergic agonists like dexemedetomidine have both analgesic and sedative properties when used as an adjuvant in regional anaesthesia. ${ }^{[6]}$ Dexmedetomidine has an eightfold greater affinity for $\alpha 2$ adrenergic receptors than clonidine and much less $\alpha 1$ activity. Its higher selectivity for $\alpha 2 \mathrm{~A}$ receptors is responsible for the hypnotic and analgesic effects. ${ }^{[7]}$ Previous studies have shown that clonidine and dexemedetomidine improved the quality of block when used as adjuvant with ropivacaine or bupivacaine in epidural block but studies are limited where levobupivacaine is used with dexmedetomidine. This study was designed to compare the analgesic, sedative action and side effects of dexmedetomidine when added to levobupivacaine for epidural analgesia in patients undergoing infraumbilical surgeries.

\section{Subjects and Methods}

Ethical committee approval and written informed consent were obtained from 60 ASA status (I / II) patients of age 20-60 years, posted for infra umbilical surgeries. This study was done from Jan 2017 to Jan 2018 in a tertiary care 
hospital. Patients with history of cardiac, respiratory, hepatic, neurological diseases and with allergy to the study drugs, were excluded from the study. ECG, pulse-oximetry (SPO2) and non-invasive blood pressure (NIBP) were monitored. Epidural anaesthesia was given in the sitting position, using 18 gauge tuohy epidural needles at L3-L4 space and epidural catheter was advanced $4 \mathrm{~cm}$ into the epidural space. A test dose of $3 \mathrm{ml}$ of $2 \%$ lignocaine solution containing adrenaline 1: 200,000 was injected. After 4-6 min of injecting the test dose and excluding intravascular or subarachnoid injection study drug was injected. Patients were allocated into two groups in double blinded fashion. Group L received $17 \mathrm{ml}$ levobupivacaine with $1 \mathrm{ml}$ normal saline and group LD received $17 \mathrm{ml}$ of $0.5 \%$ levobupivacaine and $1 \mu \mathrm{g} / \mathrm{kg}$ dexmedetomidine (diluted to $1 \mathrm{ml}$ ) through epidural catheter. The study drugs were prepared by an anaesthetist who was blind about the study. Sensory block was assessed using the blunt end of a 27-gauge needle. All durations were calculated from the time of epidural injection. The two groups were monitored pre and intra operatively for heart rate, non-invasive blood pressure and $\mathrm{O} 2$ saturation ( $\mathrm{SpO} 2)$. Intra operative nausea, vomiting, pruritus, sedation or any other side effects were recorded. Sedation was assessed by Ramsay sedation score (1: alert and awake, 2: arousable to verbal command, 3: arousable with gentle tactile stimulation, 4: arousable with vigorous shaking. 5: unarousable). Statistical Methods Data were presented as mean \pm SD. t-test was used to compare the two groups for quantitative data and chi-square test was used for qualitative data by SPSS V18. Value of $p<0.05$ was considered statistically significant.

\section{Results}

A total of 60 patients posted for infra umbilical surgeries were enrolled for the study. They were randomly divided into two groups. The demographic profiles of the patients in both the groups were comparable with regards to age, sex, height, and weight and body mass index. The ASA status of patients was similar in both the groups and mean duration of surgery was comparable in both the groups $(\mathrm{p}>0.05)$ [Table 1]. Onset of sensory block at T 10 level was earlier in group LD $(6.98 \pm 2.51 \mathrm{~min})$ compared to the group $\mathrm{L}$ (8.34 $\pm 2.95 \mathrm{~min})$. Higher dermatomal spread (T6-7) was seen in group LD in comparison to group L (T7-8). Time for maximum sensory level was shorter $(11.32 \pm 4.46 \mathrm{~min})$ in group LD compared to group L $(14.18 \pm 5.2 \mathrm{~min})$. All the above sensory block characteristics were statistically significant in group LD in comparison to group L except maximum sensory block level. Complete motor block was achieved earlier $(14.75 \pm 6.24 \mathrm{~min})$ in group LD and $18.52 \pm 5.85 \mathrm{~min}$ in group $\mathrm{L}$ which was statistically significant. $(\mathrm{p}<0.05)$. [Table 2]. Many previous studies had shown that dexmedetomidine can be used as intraoperative sedative agent. In our study mean sedation scores were significantly higher in group LD compared to group L which is statistically significant. [Table 3]. Mean time to 2 segmental dermatomal regression was $155.42 \pm 9.54 \mathrm{~min}$ and
$138.10 \pm 8.15 \mathrm{~min}$ in group $\mathrm{LD}$ and group $\mathrm{L}$ respectively. Return of motor power to bromage 1 was $258.35 \pm 27.82 \mathrm{~min}$ in L group and $285.27 \pm 26.29$ min in group LD. Both the block characteristics were statistically significant. The time for rescue analgesia was $325.94 \pm 22.58$ min in the group $\mathrm{L}$ and $354.58 \pm 26.1 \mathrm{~min}$ in group LD which was statistically significant. $(\mathrm{P}<0.05)$. [Table 4]. Parameters like heart rate, mean arterial pressure, spo 2 and respiratory rate were stable and more or less similar in both the groups throughout the study period. [Table 5] showed the comparative incidence of various side effects in both the groups which were statistically not significant. We did not observe respiratory depression in any patient in both the group.

Table 1: Demographic profile of patients of both group.

\begin{tabular}{|l|l|l|l|}
\hline $\begin{array}{l}\text { Demographic } \\
\text { characteristics }\end{array}$ & $\begin{array}{l}\text { L group } \\
(\mathbf{n = 3 0}) \text { Mean } \\
\text { + SD }\end{array}$ & $\begin{array}{l}\text { LD group } \\
(\mathbf{n = 3 0}) \text { Mean + } \\
\text { SD }\end{array}$ & $\begin{array}{l}\text { P- } \\
\text { value }\end{array}$ \\
\hline Age $(\mathrm{yrs})$ & $48.2+11.5$ & $47.2+10.8$ & 0.34 \\
\hline Sex $(\mathrm{m}: \mathrm{f})$ & $15: 15$ & $14: 16$ & 0.56 \\
\hline Weight $(\mathrm{kg})$ & $64.22+12.32$ & $64.45+11.48$ & 0.46 \\
\hline Height $(\mathrm{cm})$ & $154.8+9.58$ & $153.35+9.8$ & 0.34 \\
\hline BMI $(\mathrm{kg} / \mathrm{m} 2)$ & $26.4+2.15$ & $27.1+2.52$ & 0.67 \\
\hline ASA (I/II) & $28 / 2$ & $27 / 3$ & 1.0 \\
\hline $\begin{array}{l}\text { Mean duration of } \\
\text { surgery }(\mathrm{min})\end{array}$ & $95.12+14.5$ & $94.55+14.84$ & 0.69 \\
\hline
\end{tabular}

Table 2: Comparison of preoperative block characteristics

\begin{tabular}{|l|l|l|l|}
\hline $\begin{array}{l}\text { Block } \\
\text { characteristics }\end{array}$ & $\begin{array}{l}\text { L group } \\
(\mathbf{n}=\mathbf{3 0})\end{array}$ & $\begin{array}{l}\text { LD } \\
\text { group(n=30) }\end{array}$ & P Value \\
\hline $\begin{array}{l}\text { Onset time of } \\
\text { sensory block at T } \\
10 \text { (mins) }\end{array}$ & $8.34 \pm 2.95$ & $6.98 \pm 2.51$ & 0.002 \\
\hline $\begin{array}{l}\text { Max sensory block } \\
\text { level }\end{array}$ & T7-T8 & T6-T7 & 0.85 \\
\hline $\begin{array}{l}\text { Time to max } \\
\text { sensory block } \\
\text { (mins) }\end{array}$ & $14.18 \pm 5.2$ & $11.32 \pm 4.46$ & 0.001 \\
\hline $\begin{array}{l}\text { Time for complete } \\
\text { motor block (mins) }\end{array}$ & $18.52 \pm 5.85$ & $14.75 \pm 6.24$ & 0.01 \\
\hline $\begin{array}{l}\text { Total ephedrine } \\
\text { requirement (mg) }\end{array}$ & $7.90 \pm 2.5$ & $5.95 \pm 2.8$ & 0.12 \\
\hline
\end{tabular}

Table 3: Sedation score in both group

\begin{tabular}{|l|l|l|l|}
\hline Sedation score & L group $(\mathbf{n = 3 0})$ & LD group $(\mathbf{n}=\mathbf{3 0})$ & P value \\
\hline 1 & 20 & 7 & 0.03 \\
\hline 2 & 7 & 12 & 0.04 \\
\hline 3 & 3 & 11 & 0.04 \\
\hline 4 & 0 & 0 & 0 \\
\hline 5 & 0 & 0 & 0 \\
\hline
\end{tabular}

Table 4: Comparisons of post op block characteristics
\begin{tabular}{|l|l|l|l|}
\hline $\begin{array}{l}\text { Post op block } \\
\text { characteristics }\end{array}$ & $\begin{array}{l}\text { L group } \\
(\mathbf{n = 3 0})\end{array}$ & $\begin{array}{l}\text { LD } \\
\text { group(n=30) }\end{array}$ & $\begin{array}{l}\text { P } \\
\text { Value }\end{array}$ \\
\hline $\begin{array}{l}\text { Mean time to two } \\
\text { segment } \\
\text { regression (mins) }\end{array}$ & $138.10 \pm 8.15$ & $155.42 \pm 9.54$ & 0.0002 \\
\hline $\begin{array}{l}\text { Mean time to sensory } \\
\text { regression at S 1(mins) }\end{array}$ & $295.35 \pm 32.24$ & $342.12 \pm 33.15$ & 0.0001 \\
\hline $\begin{array}{l}\text { Mean time to regression } \\
\text { to bromage 1(mins) }\end{array}$ & $258.35 \pm 27.82$ & $285.27 \pm 26.29$ & 0.0001 \\
\hline $\begin{array}{l}\text { Time to first rescue } \\
\text { analgesia } \\
\text { (mins) }\end{array}$ & $325.94 \pm 22.58$ & $354.58 \pm 26.1$ & 0.0001 \\
\hline
\end{tabular}


Table 5: Comparison of side effects in intra and postoperative period.

\begin{tabular}{|l|l|l|}
\hline Side effect & L group $(\mathbf{n}=\mathbf{3 0})$ & LD group $(\mathbf{n}=\mathbf{3 0})$ \\
\hline Nausea & 6 & 4 \\
\hline Vomiting & 1 & 3 \\
\hline Shivering & 4 & 3 \\
\hline Headache & 0 & 2 \\
\hline Dizziness & 0 & 0 \\
\hline Dry month & 2 & 3 \\
\hline $\begin{array}{l}\text { Repiratory } \\
\text { depression }\end{array}$ & 0 & 0 \\
\hline
\end{tabular}

\section{Discussion}

Adjuvants are used with local anaesthetics in the epidural anaesthesia to prolong postoperative analgesia. Primary aim of this adjuvant is to fasten and prolong the sensory and motor block without any side effect. The pharmacologic properties of $\alpha-2$ agonists like clonidine and dexmedetomidine have been used extensively in regional blocks. Epidural administration of these drugs is associated with sedation, analgesia, anxiolysis, hypnosis and sympatholysis. ${ }^{[9]}$ Clonidine has been used as adjuvant to local anaesthetics successfully over the last few decades but it has its own side effects. About use of clonidine. The faster onset of action, and prolonged duration of analgesia in the postoperative period, makes it a very effective adjuvant to local anaesthetics in regional anaesthesia. In our study, dexmedetomidine was used as adjuvant to levobupivacaine in epidural anaesthesia in which levobupivacaine - dexmedetomidine combine produced earlier onset of epidural block, prolonged duration of sensory block and more sedation in comparison to levobupivacaine alone. There was no statistical difference in haemodynamic parameters in both groups. Disma et al in their study found that clonidine produced a local anaesthetic sparing effect with a dose dependent decrease in ED50 of levobupivacaine for caudal anaesthesia. In addition, there was a dose dependent prolongation of postoperative analgesia following lower abdominal surgery in children. A dose of $2 \mu \mathrm{g} \mathrm{kg}$ of clonidine provided the optimum balance between improved analgesia and minimal side effects. ${ }^{[10]}$ Wallet et al in their study found that the addition of clonidine to epidural levobupivacaine and sufentanil for patient controlled epidural analgesia in labour improved analgesia, reduced the supplementation rate and reduced pruritus. ${ }^{[1]}$ Milligan et al opined that, in patients undergoing total hip replacement, the addition of the alpha (2)-adrenergic agonist clonidine to epidural infusions of levobupivacaine significantly improved postoperative analgesia. ${ }^{[12]}$ Akin et al in their study found that caudal clonidine prolonged the duration of analgesia produced by caudal levobupivacaine without causing significant side effects Mahran et al, ${ }^{[13]}$ opined that both clonidine and fentanyl can be used as effective additive to epidural levobupivacaine for postoperative analgesia after radical cystectomy with no significant difference between them. ${ }^{[14]}$ Manal et al in a comparative study of epidural morphine and epidural dexmedetomidine used as adjuvant to levobupivacaine, found that dexmedetomidine was a good alternative to morphine as an adjuvant to levobupivacaine in epidural anaesthesia for major abdominal surgeries. ${ }^{[15]}$ Zeng $\mathrm{XZ}$ et al in their study found that low-dose epidural dexmedetomidine improved thoracic epidural anaesthesia for nephrectomy. Sensory and motor blockade duration was longer in the dexemedetomidine group than in the control group. Pain score and analgesic requirement was lower in dexemedetomidine group. ${ }^{[16]}$ Ahmed Sobhy Basuni et al used dexmedetomidine as adjuvant to low-dose levobupivacaine in spinal anaesthesia for knee arthroscopy. They opined that dexmedetomidine was a good alternative to fentanyl for supplementation with low-dose levobupivacaine. ${ }^{[17]}$ Aliye Esmaoglu et al concluded that intrathecal dexmedetomidine when added to levobupivacaine for spinal anaesthesia shortens sensory and motor block onset time and prolongs block duration without any significant adverse effects. ${ }^{[18]}$ Our study found Introduction of dexmedetomidine has raised question similar findings using dexmedetomidine as adjuvant to epidural levobupivacaine. El-Hennawy et al studied the effect by adding clonidine or dexmedetomidine to bupivacaine in caudal block in children. They found that addition of dexmedetomidine or clonidine to caudal bupivacaine significantly plolonged analgesia in children undergoing lower abdominal surgeries with no significant advantage of dexmedetomidine over clonidine. ${ }^{[19]} \mathrm{Al}-$ Mustafa et al. used dexmedetomidine as an intrathecal adjuvant to bupivcaine and found that its use accelerated the onset of sensory block to reach T10 dermatome. ${ }^{[20]}$ Bajwa et al showed in their study that dexmedetomidine was a better adjuvant than clonidine in epidural ropivacaine anesthesia in providing better intra-operative and postoperative analgesia. ${ }^{[21]} \mathrm{Wu} \mathrm{H}-\mathrm{H}$ et al in a retrospective study opined that neuraxial dexmedetomidine was a favorable adjuvant to local anaesthetics which provides prolonged analgesia. Neuraxial dexmedetomidine was associated with good sedation scores and lower analgesic requirements and stable intra operative hemodynamic. ${ }^{[22]}$ All the above studies showed that dexmedetomidine was a potent adjuvant to levobupivacaine in epidural anaesthesia. It provided earlier onset and prolonged sensory block. Patient comfort, satisfaction and anxiolysis was better when dexmedetomidine was used as adjuvant to levobupivacaine in epidural anaesthesia.

\section{Conclusion}

Dexmedetomidine when used as an adjuvant to epidural levobupivacaine provided prolonged sensory and motor block without any significant side effects. Epidural dexmedetomidine with levobupivacaine provided prolonged analgesia and delayed the requirement of 1 st rescue analgesia compared to levobupivacaine alone.

\section{References}

1. Tziavrangos E, Schug SA. Regional anaesthesia and perioperative outcome. Current opinion in anaesthesiology $2006 ; 19: 521-525$ 
2. Becker DE, Reed KL.Local anesthetics: review of pharmacological considerations. Anesthesia progress 2012;59:90-101.

3. Ulke ZS, Senturk M. Non-analgesic effects of thoracic epidural anesthesia. Agriculture 2007;19:6-12.

4. Huang Y, Pryor M. Mather L, Veering B. Cardiovascular and central nervous system effects of intravenous levobupivacaine and bupivacine in sheep. Anesth Analg 1998;86:797-804.

5. Bardsley H, Gristwood R. Baker H, et al. A comparision of the cardiovascular effects of levobupivacaine and racbupivacaine following intravenous administration to healthy volunteers. Brint J. Clin Pharmacol 1998; 46:245-9.

6. Kamibayashi T, Maze M. Clinical uses of alpha-2 adrenergic agonists. Anaesthesiology 2000;93:1345-9.

7. Scafati A. Analgesia and alpha agonists 2 Medens Rev 2004;4:7.

8. Mauro VA, Brandao ST. Clonidine and dexmedetomidine through epidural route for postoperative analgesia and sedation in a cholecystectomy. Rev bras Anestesiol 2004;4:1- 10.

9. Kanazi GE, Aouad MT, Jabbour Khoury SL, et al. Effect of low dose dexmedetomidine or clonidine on the characteristics of bupivacaine spinal block. Acta Anesthesiol scand 2006;50:222-7.

10. Disma N, Frawley G, Mameli L. Effect of epidural clonidine on minimum local anesthetic concentration (ED50) of levobupivacaine for caudal block in children. Paediatr Anaesth. 2011 Feb;21 (2): 128-35.

11. Wallet F, Clement JH, Bouret C. Effectts of a continuous lowdose clonidine epidural regimen on pain, satisfaction and adverse events during labour: a randomized, double-blind, placebo-controlled trial. Eur J Anaesthesiol. 2010 May; 27(5): 441-7.

12. Milligan KR, Convery PN, Weir P. The efficacy and safety of epidural infusions of levobupivacaine with and without clonidine for postoperative pain relief in patients undergoing total hip replacement. Anesth Analg. 2000 Aug; 91(2):393-7.

13. Akin A, Ocalan S, Esmaglu A. The effects of caudal or intravenous clonidine on postoperative analgesia produced by caudal levobupivacaine in children. Pediatric anesthesia 2010;20:350-355.
14. Mahran E. Ibrahim W. Is the combination of epidural clonidinelevobupivacaine has same analgesic efficacy and safety as the combination Fentanyl - levobupivacaine after radical cystectomy. Egyptian journal of anaesthesia 2014 April; 30(2): 143-147.

15. Manal M. Kamal, Sahar M. Talaat Comparative study of epidural morphine and epidural dexmedetomidine used as adjuvant to levobupivacaine in major abdominal surgery Egyptian Journal of Anaesthesia. 2014 April; 30( 2):137-141.

16. Zeng XZ; Xu YM, CuiXG. Low-dose epidural dexmedetomidine improves thoracic epidural anaesthesia for nephrectomy Anaesthesia And Intensive Care 2014 Mar;. 42(2): 185-90.

17. Ahmed Sobhy Basuni, Hoda Alsaid Ahmed Ezz. Dexmedetomidine as supplement to low-dose levobupivacaine in spinal anaesthesia for knee arthroscopy Egyptian Journal of Anaesthesia 2014 April;30( 2): 149153.

18. Aliye Esmaoglul, Sumeyra Turk ,Adnan Bayram, Aynur Akin,. The effects of Dexmedetomidine Added to Spinal Levobupivacaine for Transurethral Endoscopic Surgery, Balkan Med J 2013; 30: 186-90.

19. M. E-Hennawy, A. M. Abd-Elwahab, A.M. Abd-Elmaksoud,. Addition of clonidine or dexmedetomidine to bupivacaine prolongs caudal analgesia in children. Br. J. Anaesth. 2009;103 (2):268-274.

20. Al-Mustafa MM, Abu-Halaweh SA, Aloweida AS, et al. Effect of dexmedetomidine added to spinal bupivacaine for urological procedures. Saudi Med J. 2009;30:365-70.

21. Bajwa SJS. Bajwa SK, Kaur J, et al Dexmedetomidine and clonidine in epidural anaesthesia: a comparative evaluation. Indian J Anaesthe 2011: 55 (2): 116-21.

22. Wu H-H, Wang H-T, Jin J-J, et al. Does Dexmedetomidine as a Neuraxial Adjuvant Facilitate Better Anesthesia and Analgesia ? A Systematic Review and Meta-Analysis. PLoS ONE 2014 Mar 9(3):e93114.

Copyright: () the author(s), 2019. It is an open-access article distributed under the terms of the Creative Commons Attribution License (CC BY 4.0), which permits authors to retain ownership of the copyright for their content, and allow anyone to download, reuse, reprint, modify, distribute and/or copy the content as long as the original authors and source are cited.

How to cite this article: Patil BO, Sonavdekar SR, Mathur R. A Study on Effects of Dexmedetomidine Used as an Adjuvant in Epidural PostOperative Analgesia. Asian J. Med. Res. 2019;8(3):AN01-AN04.

DOI: dx.doi.org/10.21276/ajmr.2019.8.3.AN1

Source of Support: Nil, Conflict of Interest: None declared. 